\title{
Morphologic Correlates of Renal Growth Arrest in Neonatal Partial Ureteral Obstruction
}

\author{
ROBERT L. CHEVALIER, BENJAMIN C. STURGILL, CATHERINE E. JONES, AND \\ DONALD L. KAISER \\ Departments of Pediatrics, Pathology and Internal Medicine, University of Virginia School of Medicine, \\ Charlottesville, Virginia 22908
}

\begin{abstract}
To investigate the morphologic correlates of decreased renal blood flow and growth arrest resulting from chronic partial ureteral obstruction in the neonate, guinea pigs were subjected to unilateral ureteral constriction within the first 2 days of life and were studied at 3 and $8 \mathrm{wk}$ of age. Severity of histologic changes in the obstructed and intact contralateral kidney was assessed by light microscopy. Morphometric glomerular measurements were made using a computerized tracing device. Since contralateral nephrectomy or administration of angiotensin converting enzyme inhibitor (enalapril) result in increased blood flow to the obstructed kidney, morphologic changes were also examined in separate groups of animals subjected to these maneuvers, and were compared to appropriate controls. Ipsilateral chronic partial ureteral obstruction resulted in decreased glomerular volume $(p<0.0001)$ and increased glomerular crowding associated with tubular dilatation and progressive glomerular sclerosis, tubular atrophy, and interstitial fibrosis. The intact contralateral kidney underwent hypertrophy with increase in glomerular volume $(p<0.0001)$ and decreased glomerular density. Contralateral nephrectomy prevented the decrease in glomerular volume in the obstructed kidney and resulted in decreased glomerular density and reduced tubular atrophy at 3 wk of age. Enalapril prevented the decrease in glomerular volume at 3 wk of age, but glomerular and tubular changes progressed and were unaffected by enalapril at 8 wk. Left kidney glomerular volume was directly related to renal blood flow $(r=0.71, p<0.05)$. We conclude that renal growth arrest due to chronic partial ureteral obstruction in the neonatal guinea pig is related at least in part to renal ischemia which contributes to progressive parenchymal damage. Ischemia is mediated initially by angiotensin II and by endogenous renal growth factor(s) controlled by functional renal mass. (Pediatr Res 21: 338-346, 1987)
\end{abstract}

\section{Abbreviations}

CPUO, chronic partial ureteral obstruction RBF, renal blood flow

PAS, periodic acid-Schiff

Obstructive nephropathy remains an important cause of renal insufficiency in infancy and childhood (1). While numerous

Received July 28, 1986; accepted November 13, 1986

Correspondence and reprint requests Robert L. Chevalier, M.D., Department of Pediatrics, Box 386, University of Virginia, School of Medicine, Charlottesvillc, VA 22908

This study was supported by a grant-in-aid from the American Heart Association, and with funds contributed in part by the American Heart Association, Virginia Affiliate. R.L.C. is an Established Investigator of the American Heart Association studies have addressed the processes leading to renal dysfunction in the adult, the effects of congenital CPUO are unique due to the rapid growth and development of the kidney in postnatal life. Unfortunately, the evolution of obstructive nephropathy in children is often complicated by urinary tract infection which hastens deterioration of function and obscures the contribution of obstruction itself. We have therefore developed a model of sterile CPUO in the neonatal guinea pig in which, like the human, nephrogenesis is complete at birth and renal maturation proceeds rapidly during the first 4 postnatal wk (2).

Unilateral partial ureteral constriction within the first 2 days of life in the guinea pig results in a profound fall in RBF and arrested growth of the ipsilateral kidney, as well as increased $\mathrm{RBF}$ and hypertrophy of the contralateral kidney (2). Removal of the contralateral kidney at the time of ureteral constriction prevents the fall in RBF at $3 \mathrm{wk}$ of age, but filtration fraction remains depressed due in large part to decrease in ultrafiltration coefficient $(2,3)$. Administration of angiotensin covering enzyme inhibitor (enalapril) also improves RBF in the obstructed kidney of the 3-wk-old guinea pig (4), although the effect is smaller.

The present study was designed to elucidate the morphologic correlates of decreased RBF and renal growth arrest resulting from CPUO in the neonatal guinea pig. Animals were studied at a stage of rapid renal functional development ( $3 \mathrm{wk}$ of age) as well as at sexual maturity ( $8 \mathrm{wk}$ ). The morphologic effects of maneuvers which enhance RBF of the obstructed kidney were also investigated.

\section{METHODS}

Experiments were performed in 63 Hartley guinea pigs (male:female ratio 1:1). As shown in Table 1, animals were divided into nine groups of five to six guinea pigs per group, and were sacrificed at $3 \mathrm{wk}(23 \pm 3$ days) or $8 \mathrm{wk}$ of age (designated by prefix " 3 " or " 8 "). Animals were anesthetized with halothane within the first $48 \mathrm{~h}$ of life, and the left ureter was exposed through a midline abdominal incision. A $2-\mathrm{mm}$ length of sterilized polyethylene tubing was placed around the distal third of the left ureter to create incomplete ureteral obstruction (groups designated "OB"). The wound was closed and animals remained with their mothers until weaning at 14 days. From the 14th day until sacrifice, guinea pigs were fed standard Guinea Pig Chow (no. 5025, Purina, St Louis, MO) and were allowed to drink tap water ad libitum. In three groups (designated "E"), formation of endogenous angiotensin II was inhibited by adding enalapril maleate (Merck, Sharp \& Dohme, Rahway, NJ) to drinking water $(0.2 \mathrm{mg} / \mathrm{ml})$. Animals received approximately $30 \mathrm{mg} / \mathrm{kg} /$ day of the inhibitor, which was found to significantly inhibit the vasoconstrictor response to a test dose of angiotensin I (4). Sham operation (designated "S") was performed in lieu of ureteral constriction in control animals, and right nephrectomy (designated " $N$ ") was performed at the time of left ureteral constriction 
Table 1. Histologic scores (mean $\pm S E)^{*}$

\begin{tabular}{|c|c|c|c|c|c|c|c|c|}
\hline \multirow[b]{2}{*}{ Group } & \multirow[b]{2}{*}{$n$} & \multirow{2}{*}{$\begin{array}{l}\text { Body wt } \\
\text { (g) }\end{array}$} & \multicolumn{2}{|c|}{ Kidney wt } & \multirow{2}{*}{$\begin{array}{l}\text { Glomerular } \\
\text { sclerosis }\end{array}$} & \multirow{2}{*}{$\begin{array}{l}\text { Tubular } \\
\text { dilation }\end{array}$} & \multirow{2}{*}{$\begin{array}{l}\text { Tubular } \\
\text { atrophy }\end{array}$} & \multirow{2}{*}{$\begin{array}{l}\text { Interstitial } \\
\text { fibrosis }\end{array}$} \\
\hline & & & Wet $(g)$ & Dry $(g)$ & & & & \\
\hline \multicolumn{9}{|c|}{ Left kidney } \\
\hline \multicolumn{9}{|c|}{ 3-wk-old controls } \\
\hline \multirow[t]{2}{*}{$3 \mathrm{~S}$} & 6 & 233.3 & 1.277 & 0.255 & 0.00 & 0.08 & 0.00 & 0.00 \\
\hline & & 15.8 & 0.088 & 0.018 & 0.00 & 0.08 & 0.00 & 0.00 \\
\hline \multirow[t]{2}{*}{$3 \mathrm{SE}$} & 5 & 228.3 & 1.194 & 0.239 & 0.00 & 0.60 & 0.00 & 0.00 \\
\hline & & 13.4 & 0.063 & 0.013 & 0.00 & 0.17 & 0.00 & 0.00 \\
\hline \multirow[t]{2}{*}{$3 \mathrm{~N}$} & 5 & 222.8 & 1.636 & $0.344 \dagger$ & 0.00 & 0.20 & 0.00 & 0.00 \\
\hline & & 15.7 & 0.086 & 0.018 & 0.00 & 0.11 & 0.00 & 0.00 \\
\hline \multicolumn{9}{|c|}{ 3-wk-old CPUO } \\
\hline \multirow[t]{2}{*}{$30 \mathrm{~B}$} & 6 & 220.0 & 1.256 & 0.226 & 0.00 & $1.42 \dagger$ & $0.67 \dagger$ & $0.75 \dagger$ \\
\hline & & 8.0 & 0.135 & 0.024 & 0.00 & 0.14 & 0.19 & 0.10 \\
\hline \multirow[t]{2}{*}{$30 \mathrm{BE}$} & 6 & 198.7 & 1.214 & 0.231 & $0.50+\$$ & $1.33 \dagger$ & $0.83 \dagger$ & $0.92 \dagger$ \\
\hline & & 8.7 & 0.085 & 0.016 & 0.17 & 0.30 & 0.19 & 0.18 \\
\hline \multirow[t]{2}{*}{$30 \mathrm{BN}$} & 6 & $157.0 \dagger \ddagger$ & $2.174 \dagger \$$ & $0.391 \dagger+$ & 0.00 & $1.25 \dagger$ & 0.17 & $0.67 \dagger$ \\
\hline & & 6.4 & 0.174 & 0.031 & 0.00 & 0.28 & 0.10 & 0.10 \\
\hline \multicolumn{9}{|c|}{$\begin{array}{l}\text { 8-wk-old control and } \\
\text { CPUO }\end{array}$} \\
\hline \multirow[t]{2}{*}{$8 \mathrm{~S}$} & 5 & $386.0 \dagger$ & $1.669 \dagger$ & $0.334 \dagger$ & 0.00 & $0.00 \ddagger$ & $0.00 \neq$ & $0.00 \ddagger$ \\
\hline & & 11.4 & 0.037 & 0.007 & 0.00 & 0.00 & 0.00 & 0.00 \\
\hline \multirow[t]{2}{*}{$80 \mathrm{~B}$} & 5 & $401.2 \dagger$ & $1.164 \S$ & $0.198 \S$ & $1.05 \dagger \ddagger \S$ & $1.00 \dagger \S$ & $1.90 \dagger \neq \S$ & $2.00+\div \S$ \\
\hline & & 29.4 & 0.195 & 0.033 & 0.18 & 0.24 & 0.30 & 0.24 \\
\hline \multirow[t]{2}{*}{$80 \mathrm{BE}$} & 5 & $384.4 \uparrow$ & $1.054 \S$ & $0.179 \dagger \S$ & $1.20 \dagger \ddagger \S$ & $1.40 \dagger \S \S$ & $2.20 \dagger \ddagger \S$ & $2.50+千 \S$ \\
\hline & & 27.6 & 0.164 & 0.028 & 0.23 & 0.17 & 0.36 & 0.28 \\
\hline \multicolumn{9}{|c|}{ 8-wk vs. 3-wk groups } \\
\hline \multicolumn{2}{|c|}{$p$} & $<0.0001$ & NS & NS & $<0.0003$ & $<0.0001$ & $<0.0001$ & $<0.0001$ \\
\hline \multicolumn{9}{|l|}{ Right kidney } \\
\hline $3 \mathrm{~S}$ & & & 1.274 & 0.255 & 0.00 & 0.08 & 0.00 & 0.00 \\
\hline & & & 0.114 & 0.023 & 0.00 & 0.08 & 0.00 & 0.00 \\
\hline $3 \mathrm{SE}$ & & & 1.168 & 0.234 & 0.00 & 0.20 & 0.00 & 0.00 \\
\hline & & & 0.033 & 0.007 & 0.00 & 0.11 & 0.00 & 0.00 \\
\hline $30 \mathrm{~B}$ & & & $1.661 \dagger \|$ & $0.332 \uparrow \|$ & 0.00 & $0.08 \S$ & $0.00 \S$ & $0.00 \S$ \\
\hline & & & 0.069 & 0.014 & 0.00 & 0.08 & 0.00 & 0.00 \\
\hline $30 \mathrm{BE}$ & & & $1.219 \ddagger$ & $0.256 \$$ & $0.00 \S$ & $0.00 \S$ & $0.00 \S$ & $0.00 \S$ \\
\hline & & & 0.065 & 0.014 & 0.00 & 0.00 & 0.00 & 0.00 \\
\hline $8 \mathrm{~S}$ & & & $1.613 \dagger$ & $0.323 \dagger$ & 0.00 & 0.00 & 0.10 & 0.00 \\
\hline & & & 0.046 & 0.009 & 0.00 & 0.00 & 0.10 & 0.00 \\
\hline $80 \mathrm{~B}$ & & & $2.287+\neq \S \|$ & $0.457 \dagger \ddagger \S \|$ & $0.10 \S$ & $0.00 \S$ & $0.00 \S$ & $0.00 \S$ \\
\hline & & & 0.088 & 0.018 & 0.09 & 0.00 & 0.00 & 0.00 \\
\hline $80 \mathrm{BE}$ & & & $2.339+\ddagger \S \|$ & $0.468+\ddagger \S \|$ & $0.20 \S$ & $0.10 \S$ & $0.10 \S$ & $0.00 \S$ \\
\hline & & & 0.108 & 0.022 & 0.18 & 0.09 & 0.09 & 0.00 \\
\hline
\end{tabular}

* Abbreviations: S, sham; E, enalapril; N, right nephrectomy; OB, left ureteral obstruction; 3, 3 wk of age; 8,8 wk of age.

$\dagger p<0.05$ versus $3 \mathrm{~S}$.

$\$ p<0.05$ versus $30 \mathrm{~B}$.

$\S p<0.05$ versus $8 \mathrm{~S}$.

$\| p<0.05$ versus left kidney.

in two groups as shown in Table 1. Animals with both left ureteral constriction and right nephrectomy had decreased somatic growth and died of uremia between 3 and 8 wk of age (2) and therefore could not be studied at $8 \mathrm{wk}$. We have previously shown that urine produced by the obstructed kidney is sterile (2).

After sacrifice of each animal by intraperitoneal injection of sodium pentobarbital and intravenous infusion of saturated potassium chloride, kidneys were excised, drained, weighed, bisected, and fixed in buffered $10 \%$ formalin. Half of the kidney was weighed before and after drying at $40^{\circ} \mathrm{C}$ for 10 days to determine dry weight. The remaining half of each kidney was embedded in paraffin, and longitudinal sections $7-\mu \mathrm{m}$ thick were stained with hematoxylin/eosin and PAS for examination by light microscopy. Histologic changes were scored in blind fashion by two independent observers and the scores were averaged for each parameter using the following scale: $0=$ no pathologic change (normal) $; 1=$ mild changes; $2=$ moderate changes; $3=$ severe changes. The cortex and medulla were scanned in a saggital section of each of 87 kidneys. Parameters examined included glomerular sclerosis, tubular dilatation, tubular atrophy, and interstitial fibrosis. Glomerular sclerosis was defined as an increase in dense PAS-positive material replacing the cellular mesangium. Tubular dilatation was defined as an increase in tubular luminal area accompanied by flattening of the tubular epithelium. The latter was not present in tubular enlargement 
characterizing normal or compensatory renal growth. Vascular changes and interstitial cellular infiltrate were also sought, but vessels were normal and cellular infiltrate was present focally in only one kidney of group 30BE.

Glomerular density was quantitated for each kidney by counting the number of glomeruli in five nonoverlapping squares of $0.64 \mathrm{~mm}^{2}$. Care was taken to include both outer and inner cortex (and no medulla) for each determination, which was made with a magnification factor of $225 \times$ using a computerized tracing device (Videoplan, Zeiss, West Germany) connected to a videocamera (Dage 68, Leitz, West Germany) mounted on a microscope (BME Orthoplan, Leitz, West Germany). The mean value for each group was obtained by averaging the number of observations within the group.

The mean area of Bowman's capsule and the glomerular tuft was also measured using the computerized tracing equipment and a magnification factor of $900 \times$. To sample both superficial and deep glomeruli, an interlobular artery was identified in each kidney section, and the area of Bowman's capsule and the enclosed glomerular tuft were measured for 10 glomeruli from the surface of the kidney to the juxtamedullary area. The volume of the glomerular tuft was calculated by assuming an idealized sphere using the formula developed by Weibel (5):

\section{glomerular tuft volume $=1.25 \times(\text { glomerular tuft area })^{3 / 2}$}

The constant (1.25) was derived from the ratio of the shape coefficient for spheres (1.38) and a size distribution coefficient (1.1) (5). The volume of Bowman's capsule was similarly calculated, and Bowman's space volume was derived from the difference of the two. The mean value for each group was obtained by averaging the total number of measurements within the group.

For three glomeruli in each kidney, the total luminal crosssectional area of all identifiable glomerular capillaries was measured in addition to the total glomerular tuft area, using a magnification factor of $1450 \times$. The ratio of glomerular capillary cross-sectional area to total glomerular tuft area was computed for each glomerulus.

For 10 sham-operated guinea pigs and four animals subjected to CPUO, hemodynamic studies were performed at $8 \mathrm{wk}$ of age under pentobarbital anesthesia. RBF was measured by radioactive microsphere technique and the number of perfused glomeruli per kidney was determined by in vivo India ink infusion as described previously (2). Results of RBF and number of perfused glomerular for 3-wk-old groups have been reported previously $(2,4,6,7)$ and are summarized in Table 3 for comparison.

Statistical analysis. The data in each group were judged to be normally distributed. Comparisons for each parameter between groups and between left and right kidney were made using a general linear model and two-way analysis of variance (S.A.S. Institute, Cary, NC). Specific group comparisons were made using least-square means with the standard error estimate derived from analysis of variance. The relationship between kidney weight and histologic parameters was examined by multiple regression analysis. The relationship of glomerular density to kidney weight and of glomerular volume to RBF was determined by the method of least squares. $p<0.05$ was considered significant for all statistical comparisons.

\section{RESULTS}

Kidney weight and gross appearance. As shown in Table 1, data are presented in three sets of three groups each: 3-wk-old controls (3S) with controls for enalapril (3SE) and uninephrectomy $(3 \mathrm{~N})$; 3-wk-old animals with CPUO (30B), and CPUO with enalapril (30BE) or uninephrectomy $(30 \mathrm{BN})$; and 8-wk-old animals: controls (8S), CPUO (80B), and CPUO with enalapril (80BE). Body weight at the time of sacrifice did not differ between 3-wk-old groups except for significantly smaller weight gain in group $30 \mathrm{BN}$. Body weight nearly doubled from 3 to $8 \mathrm{wk}$ in animals with two kidneys, and there was no effect of long-term
CPUO or enalapril administration on somatic growth. Enalapril administration had no effect on growth of left or right kidneys regardless of CPUO or age. Uninephrectomy alone (group $3 \mathrm{~N}$ ) resulted in a $28 \%$ increase in left kidney wet weight compared to group $3 \mathrm{~S}$ which was of borderline significance $(p=0.07)$. However, uninephrectomy and CPUO (group 30BN) resulted in a $70 \%$ increase in left kidney wet weight versus group $30 \mathrm{~B}$ and $33 \%$ increase versus group $3 \mathrm{~N}(p<0.0001)$. As a result of normal renal growth from 3 to 8 wk of age, mass of both kidneys increased approximately $30 \%$ (8S versus $3 \mathrm{~S}$ ). Compared to respective sham groups, although CPUO did not affect left kidney wet weight at 3 wk of age (groups $30 \mathrm{~B}$ and $30 \mathrm{BE}$ ), normal renal growth was prevented (groups $80 \mathrm{~B}$ and $80 \mathrm{BE}$ ). The intact right kidney demonstrated compensatory hypertrophy at 3 wk (group 30B) which increased further at 8 wk (group 80B). Administration of enalapril prevented early hypertrophy of the right kidney at $3 \mathrm{wk}$ (group $30 \mathrm{BE}$ ), but this effect did not persist at $8 \mathrm{wk}$ (group $80 \mathrm{BE}$ ). As a result of CPUO, the left ureter was dilated and tortuous, and the renal pelvis was dilated with mild thinning of the parenchyma at $3 \mathrm{wk}$ which became more pronounced at 8 wk. In animals with left CPUO and contralateral nephrectomy dying at 3 to $8 \mathrm{wk}$ of age, the kidney was grossly enlarged (wet weight $=5.66 \pm 0.78 \mathrm{~g} ; n=6$ ). Changes in dry kidney weight paralleled those of wet weight (Table 1).

Histologic changes. As shown in Table 1 and Figures 1 and 2, glomerular sclerosis was not present in either kidney of control animals, and was not apparent with CPUO at $3 \mathrm{wk}$ except for minimal changes in animals receiving enalapril (group 30BE). There was significant development of glomerular sclerosis in obstructed kidneys of 8 -wk-old guinea pigs (Fig. 2), with approximately $30 \%$ of glomeruli being affected (groups $80 \mathrm{~B}$ and $80 \mathrm{BE}$ ). Tubules were consistently dilated in the obstructed kidney but dilatation did not progress from 3 to $8 \mathrm{wk}$ of age (Table 1, Figs. 1 and $2 B$ and $D$ ). There was no correlation between left kidney weight and tubular dilatation $(r=0.09, p=\mathrm{NS})$, but glomerular sclerosis was related to tubular dilatation $(r=0.41, p<0.005)$.

Tubular atrophy and interstitial fibrosis were virtually absent in all intact kidneys and were present in patchy distribution in all obstructed kidneys, will the exception of group 30BN in which tubular atrophy was minimal (Table 1, Figs. 1 and 2). There was progression of severity of tubular atrophy and interstitial fibrosis in obstructed kidneys from 3 to $8 \mathrm{wk}$ of age $(p<$ $0.0001)$. Left kidney wet weight was inversely correlated with tubular atrophy $(r=-0.38, p<0.01)$, and tubular atrophy was closely correlated with interstitial fibrosis $(r=0.96, p<0.0001)$. Glomerular sclerosis was highly correlated with the severity of tubular atrophy $(r=0.89, p<0.0001)$, while tubular dilation and tubular atrophy were less closely related $(r=0.48, p<$ $0.001)$. Mesangial matrix was more prominent in glomeruli of both kidneys of all eight compared to 3-wk-old guinea pigs (Fig. 2). There was no apparent difference between outer and inner cortex in any of the histologic parameters examined at either 3 or 8 wk of age.

Glomerular density and volume. As shown in Table 2, glomerular density was not significantly affected by normal growth of either kidney from 3 to $8 \mathrm{wk}$ of age (group $8 \mathrm{~S}$ versus 3S). Left CPUO resulted in significant glomerular crowding only after 8 wk (group 80B), while contralateral nephrectomy caused greater separation of glomeruli in the cortex (group 30BN). Administration of enalapril resulted in increased glomerular density for the right kidney of 3-wk-old guinea pigs (groups 3SE and 30BE) and decreased density at $8 \mathrm{wk}$ (group 80BE). There was a significant negative correlation between glomerular density and wet kidney weight $(r=-0.68, p<0.0001)$, which was stronger for obstructed kidneys of 3-wk-old animals $(r=-0.88, p<0.001)$.

As a result of normal growth from 3 to $8 \mathrm{wk}$ of age (group $8 \mathrm{~S}$ versus 3S), glomerular volume increased approximately $30 \%$ ( $p$ $<0.0001$ ) (Table 2), which is proportional to the increase in kidney weight (Table 1). Administration of enalapril did not affect glomerular volume of the intact kidneys (group 3SE), while 


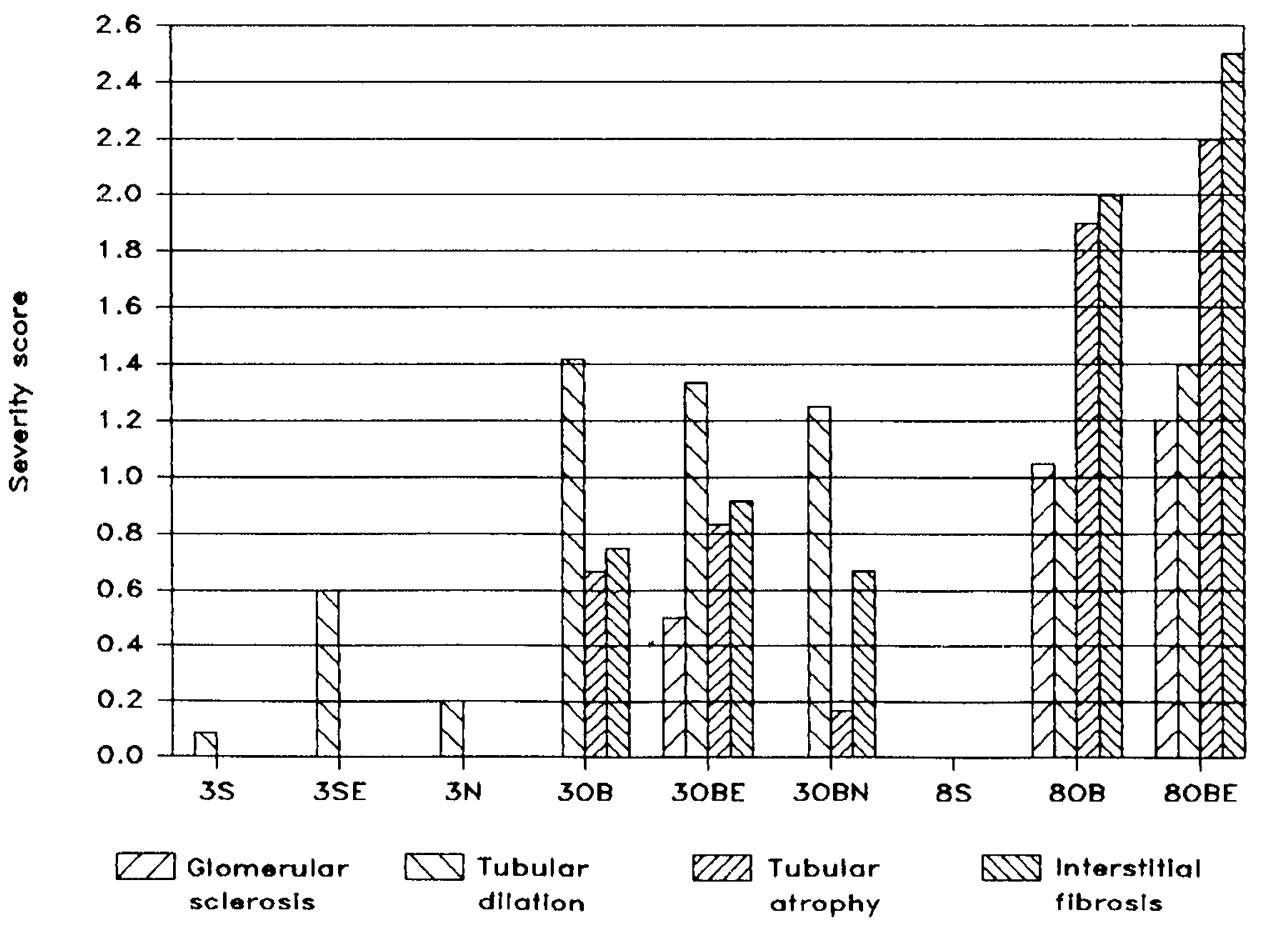

Fig. 1. Histologic changes. Mean severity score for each group of histologic parameters examined in the left kidney.

contralateral nephrectomy caused a $46 \%$ increase in volume ( $p$ $<0.0001$ ) (group $3 \mathrm{~N}$ ). At 3 wk of age, left CPUO resulted in a $28 \%$ reduction in glomerular volume $(p<0.0001)$ (group 30B), an effect which was prevented by either enalapril administration (group 30BE) or contralateral nephrectomy (group 30BN). In group 3S, there was a progressive increase in glomerular volume from outer $\left(0.202 \pm 0.046 \times 10^{-6} \mu \mathrm{m}^{3}\right)$ to inner cortex $(0.440 \pm$ $\left.0.096 \times 10^{-6} \mu \mathrm{m}^{3}\right)(r=0.34, p<0.01)$. This difference was eliminated by CPUO in the left kidney of group 30B, in which subcapsular glomerular volume was $0.183 \pm 0.032 \times 10^{-6} \mu \mathrm{m}^{3}$ compared to $0.193 \pm 0.035 \times 10^{-6} \mu \mathrm{m}^{3}$ for inner cortex $(r=$ $0.03, p=\mathrm{NS})$. Thus, the effect of CPUO on glomerular volume appears to be primarily on deeper nephrons. The relative increase in glomerular volume in group 30BN remained significantly less than in animals with uninephrectomy alone (group $3 \mathrm{~N})(p<$ $0.0001)$. At 8 wk of age, CPUO was associated with persistent decrease in glomerular volume (group $80 \mathrm{~B}$ versus $8 \mathrm{~S}, p<0.0001$ ), but volume had increased $38 \%$ compared to 3 wk (group 30B). At $8 \mathrm{wk}$, enalapril administration no longer caused an increase in glomerular volume of the obstructed kidney (group 80BE versus $80 \mathrm{~B}$ ). Glomerular volume of the hypertrophied right kidney was increased at $3 \mathrm{wk}$ (Table 2 , group 30B versus 3S), and increased further at 8 wk $(p<0.0001)$ (group 80B) in proportion to increase in kidney weight (Table 1).

The results of mean renal blood flow measured in identical groups of animals are summarized in Table 3 . The relationship of mean glomerular volume to mean RBF for each group of 3wk-old guinea pigs is shown in Figure 3. There is a linear correlation between left kidney glomerular volume and RBF $(r$ $=0.71, p<0.05)$, which is stronger when only 3 -wk-old groups are included $(r=0.89, p<0.01)$.

Bowman's space volume. Bowman's space volume of the left kidney was unaffected by normal or compensatory growth (Table 2 , groups $8 \mathrm{~S}$ and $3 \mathrm{~N}$ versus $3 \mathrm{~S}$ ). Left CPUO also did not alter Bowman's space volume at either age (groups 30B and 80B), while contralateral nephrectomy caused an increase (group $30 \mathrm{BN}$ ). Administration of enalapril resulted in decreased Bowman's space volume of the obstructed kidney at 3 wk (group $30 \mathrm{BE}$ ) and increased volume at $8 \mathrm{wk}$ (group 80BE). For the right kidney, the volume of Bowman's space decreased significantly with normal growth from 3 to $8 \mathrm{wk}$ of age, as well as during enalapril administration at 3 (but not 8) wk of age. Bowman's space volume was increased in the right kidney of 8 -wk-old animals with left CPUO (Table 2).

Glomerular capillary area. The ratio of glomerular capillary cross-sectional area to total glomerular tuft area is shown in Table 2. This parameter represents an index of the proportion of the glomerular tuft available for glomerular perfusion, but does not necessarily relate to the surface area available for filtration $(8,9)$. There was no signficant effect of CPUO, uninephrectomy, or enalapril on the left kidney ratio for 3-wk-old animals, whereas the ratio decreased consistently by $8 \mathrm{wk}$ regardless of the presence of obstruction or enalapril (Table 2). In the right kidney, the ratio increased with hypertrophy at $3 \mathrm{wk}$ (groups $30 \mathrm{~B}$ and $30 \mathrm{BE}$ ) but decreased at $8 \mathrm{wk}$ in all groups. The mesangium appeared to be more prominent in both kidneys of 8-wk compared to 3-wkold groups.

\section{DISCUSSION}

Determinants of renal growth. Increase in renal size is influenced by changes in parenchymal structure as well as renal water content. We found no change in renal water content with normal growth from 3 to $8 \mathrm{wk}$ of age, and a relatively small increase resulting from CPUO. Differences in kidney weight should therefore be explainable by differences in vascular/glomerular, tubular, or interstitial composition, which were examined in this study. In addition, since renal growth is dependent on renal perfusion (10), and CPUO is characterized by vasoconstriction (2), we have sought to correlate morphologic changes with RBF. Since there was no significant difference among 3-wk-old groups in the ratio of glomerular capillary area to glomerular tuft area in the left kidney, correlation of total glomerular volume with $\mathrm{RBF}$ is justified. The poorer correlation of glomerular volume with RBF for combined 3- and 8-wk-old groups presumably relates to the greater mesangial content of older kidneys.

The control of renal growth appears to be under the influence of circulating and tissue-derived growth factors (renotropins) and inhibitors (11). Reduction in functional renal mass by uninephrectomy or unilateral ureteral obstruction results in compensatory hypertrophy and functional adaptation of the contralateral kidney (12). This led to the early concept of "renal counterbal- 

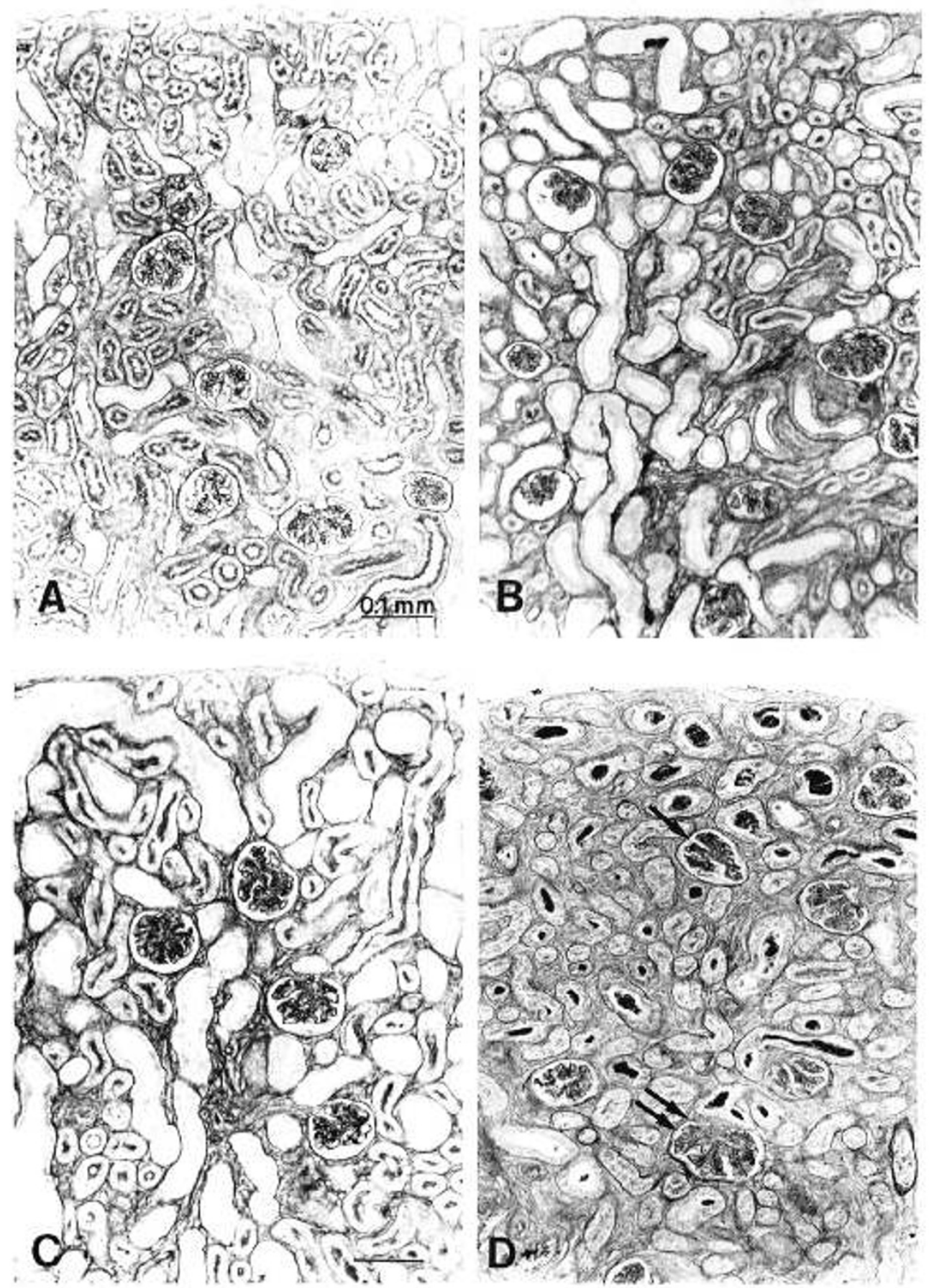

Fig. 2. Histologic appearance of kidneys. A, right (intact) kidney of 3-wk-old guinea pig subjected to left CPUO (group 30B). Glomeruli and tubules appear normal with no interstitial fibrosis. $B$, left (obstructed) kidney of same animal (group 30B). Glomeruli show ischemic contraction, distal tubules are dilated, and there is mild interstitial fibrosis. $C$, left (obstructed) kidney of 3-wk-old guinea pig subjected to left $C P U O$ and right nephrectomy (group 30BN). Glomeruli are enlarged with dilated tubules and mild interstitial fibrosis. $D$, left (obstructed) kidney of 8-wk-old guinea pig subjected to CPUO (group 80B). Glomeruli are contracted with moderate sclerosis (arrow) and mesangial expansion (double arrows). There are many atrophic tubules and interstitial fibrosis is more pronounced than at $3 \mathrm{wk}$

ance" which implied compensation of intact nephrons for impaired function of the remainder (13). It appears that compensatory adaptation to reduced renal mass during early postnatal development is largely the result of acceleration and amplification of normal functional maturation $(6,7,14)$. To interpret the present study, we therefore considered the effects of CPUO on normal and compensatory renal growth, as well as the effects of compensatory growth on CPUO.

Effects of CPUO on normal renal growth. Since kidney weight of 1-day-old guinea pigs is $0.5 \mathrm{~g}(6)$, comparison of $\mathrm{OB}$ with $\mathrm{S}$ groups at 3 and $8 \mathrm{wk}$ of age reveals that CPUO results in slowing and arrest of normal renal growth rather than regression. Although judging from kidney weight, the obstructed kidney appeared to grow at a near-normal rate for the first $3 \mathrm{wk}$, there were marked parenchymal changes including reduction in glomerular volume, tubular dilatation, tubular atrophy, and development of interstitial fibrosis. Maintenance of normal kidney weight at this age is therefore presumably due in part to tubular dilatation and increased water content. Increase in glomerular volume following enalapril adminstration in group 30BE and 
Table 2. Morphometric data*

\begin{tabular}{|c|c|c|c|c|c|c|c|}
\hline Group & $n$ & $\begin{array}{c}\text { Glomerular } \\
\text { density } \\
\left(\text { no. } / \mathrm{mm}^{2}\right)\end{array}$ & $n$ & $\begin{array}{l}\text { Glomerular } \\
\text { volume } \\
\left(\times 10^{-6} \mu \mathrm{m}^{3}\right)\end{array}$ & $\begin{array}{c}\text { Bowman's space } \\
\text { volume } \\
\left(\times 10^{-6} \mu \mathrm{m}^{3}\right)\end{array}$ & $n$ & $\begin{array}{c}\text { Glomerular } \\
\text { capillary/tuft } \\
\text { area ratio }\end{array}$ \\
\hline \multicolumn{8}{|c|}{ Left kidney } \\
\hline \multicolumn{8}{|c|}{ 3-wk-old controls } \\
\hline \multirow[t]{2}{*}{$3 \mathrm{~S}$} & 30 & 3.61 & 60 & 0.255 & 0.075 & 18 & 0.35 \\
\hline & & 0.25 & & 0.011 & 0.004 & & 0.01 \\
\hline \multirow[t]{2}{*}{$3 \mathrm{SE}$} & 25 & 4.04 & 50 & 0.231 & 0.064 & 15 & 0.35 \\
\hline & & 0.29 & & 0.011 & 0.004 & & 0.01 \\
\hline \multirow[t]{2}{*}{$3 \mathrm{~N}$} & 25 & 3.20 & 50 & $0.372 \dagger$ & 0.084 & 15 & 0.34 \\
\hline & & 0.19 & & 0.016 & 0.005 & & 0.01 \\
\hline \multicolumn{8}{|l|}{ 3-wk-old CPUO } \\
\hline \multirow{2}{*}{$30 \mathrm{~B}$} & 30 & 4.18 & 60 & $0.184 \dagger$ & 0.070 & 18 & 0.41 \\
\hline & & 0.25 & & 0.006 & 0.004 & & 0.02 \\
\hline \multirow[t]{2}{*}{$30 \mathrm{BE}$} & 30 & 4.25 & 60 & $0.244 \$$ & $0.053+\ddagger$ & 18 & 0.40 \\
\hline & & 0.36 & & 0.010 & 0.004 & & 0.02 \\
\hline \multirow[t]{2}{*}{$30 \mathrm{BN}$} & 30 & $2.26 \dagger \ddagger$ & 60 & $0.261 \neq$ & $0.096 \dagger \ddagger$ & 15 & 0.38 \\
\hline & & 0.19 & & 0.010 & 0.005 & & 0.02 \\
\hline \multicolumn{8}{|c|}{$\begin{array}{l}\text { 8-wk-old control and } \\
\text { CPUO }\end{array}$} \\
\hline \multirow[t]{2}{*}{$8 \mathrm{~S}$} & 25 & 3.30 & 50 & $0.326+\uparrow$ & 0.069 & 15 & $0.26 \uparrow \neq$ \\
\hline & & 0.26 & & 0.012 & 0.007 & & 0.02 \\
\hline \multirow[t]{2}{*}{$80 \mathrm{~B}$} & 25 & $4.48+\S$ & 50 & $0.253 \neq \S$ & 0.082 & 15 & $0.26 \dagger \neq$ \\
\hline & & 0.70 & & 0.013 & 0.005 & & 0.01 \\
\hline \multirow[t]{2}{*}{ 80BE } & 25 & 4.07 & 50 & $0.247+\S$ & $0.096+\cdot \S$ & 15 & $0.26+\div$ \\
\hline & & 0.39 & & 0.011 & 0.006 & & 0.02 \\
\hline \multicolumn{8}{|l|}{ Right kidney } \\
\hline \multirow[t]{2}{*}{$3 \mathrm{~S}$} & 30 & 3.18 & 60 & 0.264 & 0.080 & 18 & 0.34 \\
\hline & & 0.26 & & 0.011 & 0.004 & & 0.02 \\
\hline \multirow[t]{2}{*}{$3 \mathrm{SE}$} & 25 & $4.25+\ddagger$ & 50 & 0.237 & $0.064 \dagger$ & 15 & $0.40 \dagger$ \\
\hline & & 0.25 & & 0.011 & 0.004 & & 0.01 \\
\hline \multirow[t]{2}{*}{$30 \mathrm{~B}$} & 30 & $3.16 \|$ & 60 & $0.310+\cdot \|$ & $0.058+\|$ & 18 & $0.40 \dagger$ \\
\hline & & 0.27 & & 0.015 & 0.004 & & 0.03 \\
\hline \multirow[t]{2}{*}{$30 \mathrm{BE}$} & 30 & $4.29+末$ & 60 & $0.306 \|$ & $0.042 \uparrow+\|$ & 18 & $0.41 \dagger$ \\
\hline & & 0.20 & & 0.012 & 0.002 & & 0.03 \\
\hline \multirow[t]{2}{*}{$8 S$} & 25 & 3.48 & 50 & $0.353 \dagger$ & $0.066 \uparrow$ & 15 & $0.22 \dagger$ \\
\hline & & 0.22 & & 0.012 & 0.005 & & 0.01 \\
\hline \multirow[t]{2}{*}{$80 \mathrm{~B}$} & 25 & $2.76 \|$ & 50 & $0.569 \dagger \uparrow \S \S^{\prime} \|$ & $0.087 \ddagger \S$ & 15 & $0.31 \dagger$ \\
\hline & & 0.24 & & 0.025 & 0.006 & & 0.02 \\
\hline \multirow[t]{2}{*}{$80 \mathrm{BE}$} & 25 & $2.18 \dagger \ddagger \S \|$ & 50 & $0.501 \uparrow \ddagger \S$ & $0.091 \neq \S$ & 15 & $0.30 \dagger$ \\
\hline & & 0.19 & & 0.025 & 0.006 & & 0.02 \\
\hline
\end{tabular}

* Footnotes are the same as Table 1.

Table 3. RBF and number of perfused glomeruli*

\begin{tabular}{|c|c|c|c|c|c|c|}
\hline \multirow[b]{2}{*}{ Group } & \multicolumn{3}{|c|}{ Renal blood flow $(\mathrm{ml} / \mathrm{min})^{a}$} & \multicolumn{3}{|c|}{$\begin{array}{l}\text { Number of perfused glomeruli }{ }^{b} \text { per kidney } \\
\text { (thousands) }\end{array}$} \\
\hline & $n$ & Left kidney & Right kidney & $n$ & Left kidney & Right kidney \\
\hline $3 \mathrm{~S}$ & 13 & $4.96 \pm 0.51$ & $4.63 \pm 0.47$ & $8 / 5$ & $67.35 \pm 2.42$ & $59.52 \pm 1.91$ \\
\hline $3 \mathrm{SE}$ & 9 & $5.74 \pm 0.76 \ddagger$ & $5.81 \pm 0.86$ & 6 & $88.87 \pm 4.43 \dagger \neq$ & $82.52 \pm 3.35 \dagger$ \\
\hline $3 N$ & 11 & $7.31 \pm 0.75 \dagger+$ & & 8 & $83.99 \pm 3.23 \dagger \ddagger$ & \\
\hline $30 \mathrm{~B}$ & 19 & $2.58 \pm 0.26 \dagger$ & $7.96 \pm 0.68 \dagger \|$ & 9 & $63.06 \pm 3.72$ & $79.27 \pm 2.25+\|$ \\
\hline $30 \mathrm{BE}$ & 20 & $4.73 \pm 0.48 \ddagger$ & $9.93 \pm 0.91 \dagger \|$ & 7 & $79.63 \pm 2.73+\ddagger$ & $83.46 \pm 2.39 \dagger$ \\
\hline $30 \mathrm{BN}$ & 10 & $5.31 \pm 0.82 \ddagger$ & & 6 & $84.25 \pm 4.01+\neq$ & \\
\hline $8 \mathrm{~S}$ & 10 & $8.63 \pm 0.99+\downarrow$ & $8.88 \pm 1.57$ & 5 & $87.04 \pm 2.79 \dagger \ddagger$ & $78.13 \pm 4.36 \dagger \|$ \\
\hline $80 \mathrm{~B}$ & 4 & $1.15 \pm 0.25+\S$ & $6.45 \pm 0.96 \S$ & 4 & $58.09 \pm 4.61 \S$ & $85.90 \pm 2.87 \dagger \|$ \\
\hline
\end{tabular}

* Footnotes are the same as Table 1.

" Measured by radioactive microsphere technique. Values for 3-wk-old animals previously reported in References 2,4 , and 7.

"Determined by India ink perfusion. Values for 3-wk-old animals previously reported in References 2,4 , and 6. 


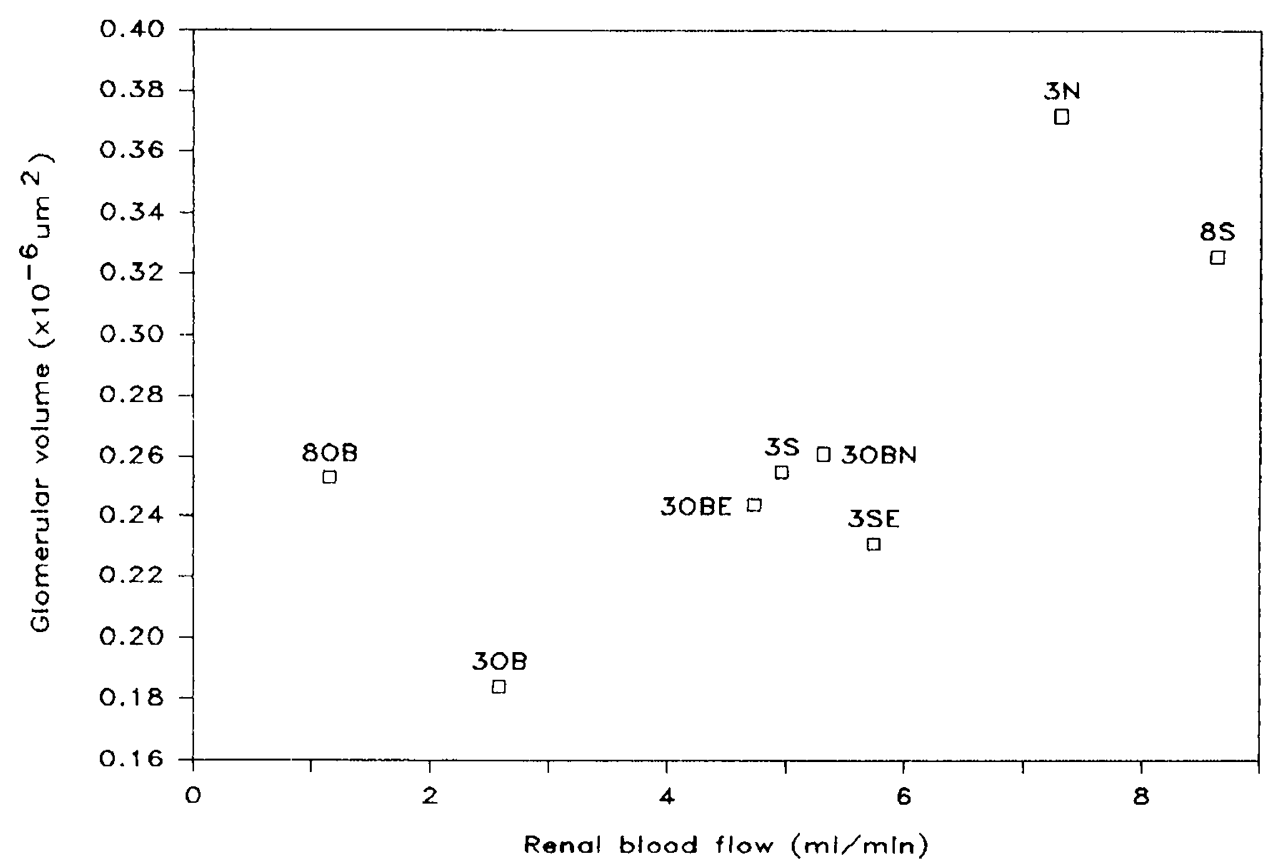

Fig. 3. Relationship of left kidney glomerular volume to RBF. Mean glomerular volume for the left kidney of each of the 3-wk-old groups is related to total left RBF measured by radioactive microspheres and reported previously for 3-wk-old guinea pigs (References 2,4 , and 7$)(r=0.71$, $p<0.05)$.

the close correlation between glomerular volume and RBF indicate that glomerular volume is at least in part dependent on $\mathrm{RBF}$. In this respect, it is of interest that glomerular volume did not increase with enalapril in the control group (3SE). Previous studies in the rat have shown that angiotensin-induced changes in glomerular volume vary with nephron population and with the dose of angiotensin infused $(15,16)$. Since angiotensinmediated vasoconstriction is enhanced in the obstructed compared to the intact kidney (4), it is not surprising that glomerular volume also differs. However, lack of effect of enalapril on tubular atrophy and interstitial fibrosis in the obstructed kidney suggests that the postglomerular circulation is primarily affected by other factors.

Although normal growth resulted in a $30 \%$ increase in kidney weight in sham groups, there was no change in weight of the obstructed kidney from 3 to $8 \mathrm{wk}$ of age. During this interval, glomerular volume increased but glomerular capillary crosssectional area failed to increase proportionately, presumably due to mesangial expansion and glomerular sclerosis. By 8 wk of age, chronic enalapril administration no longer resulted in glomerular changes while tubular atrophy and interstitial fibrosis progressed in severity. Maintenance of number of perfused glomeruli (Table 3 ), the presence of glomerular crowding, and lack of obsolescent glomeruli in the obstructed kidney at 8 wk indicate that contraction of tubular elements is proportionately greater than nephron "drop out."

Effects of CPUO on compensatory renal hypertrophy. Comparison of groups $30 \mathrm{BN}$ and $3 \mathrm{~N}$ reveals that the compensatory increase in glomerular volume was impaired by ipsilateral CPUO, while increased wet kidney weight and decreased glomerular density were due to tubular enlargement exceeding that resulting from hypertrophy alone.

Although mass of the obstructed left kidney in 3-wk-old animals (group 30B) was not less than that of controls (group 3S), weight and glomerular volume of the intact right kidney were significantly greater than the left. Of interest is the effect of enalapril administration on growth of the right kidney at $3 \mathrm{wk}$. There appeared to be a lack of compensatory hypertrophy of the right kidney in group 30BE (manifested by lower kidney weight and increased glomerular density), and volume of Bowman's space was less than that in group $30 \mathrm{~B}$. These changes were associated with greater glomerular volume (and RBF) of the obstructed left kidney resulting from enalapril treatment. These findings are consistent with nephron growth (both glomerular and tubular) being regulated by function (or perfusion) of the contralateral kidney, rather than by total renal mass. In support of this hypothesis, the biochemical correlates of renal hypertrophy following contralateral ureteral obstruction are indistinguishable from those resulting from contralateral nephrectomy (17, 18). However, at $8 \mathrm{wk}$ of age, enalapril had no effect on growth, glomerular volume, or glomerular density of either kidney.

The influence of age was examined by Taki et al. (19) who showed that CPUO in the young guinea pig caused more severe impairment of growth and function of the ipsilateral kidney but enhanced hypertrophy of the contralateral kidney compared to adults. It therefore appears that "renal counterbalance" may be exaggerated in early development, at which time the kidney is most susceptible to injury but also most capable of compensatory growth.

Effects of compensatory renal growth on CPUO. Comparison of group $30 \mathrm{BN}$ with $30 \mathrm{~B}$ reveals increased glomerular volume proportional to the increase in RBF of the left kidney. Whereas the functional consequences of CPUO appear to be lessened in the hypertrophied kidney as evidenced by better preservation of RBF at 3 wk (2), the morphologic correlate revealed by the present study is reduced tubular atrophy. Although the degree of tubular dilatation did not appear to be greater in group $30 \mathrm{BN}$ than in $30 \mathrm{~B}$, an increased number of perfused glomeruli (Table 3) and decreased glomerular density suggest that tubular volume is primarily increased by tubular lengthening as shown by microdissection studies (20). A salutary effect of compensatory renal growth on CPUO in the adult rat was also demonstrated by Arnold (21) who found that contralateral nephrectomy prevented development of interstitial fibrosis and renal atrophy.

Pathogenesis of renal injury in neonatal CPUO. In view of the marked decrease in RBF and glomerular shrinkage which occur in the obstructed kidney, it is likely that ischemia contributes to the morphologic changes observed. In the rat, renal artery stenosis results in atrophy of the affected kidney, while hypertrophy following contralateral nephrectomy is impaired in the ischemic kidney (10). Histologically, ischemic kidneys revealed tubular atrophy and glomerular crowding similar to findings in the present study (10).

It appears that reduction in glomerular blood flow due to 
UNILATERAL PARTIAL URETERAL OBSTRUCTION

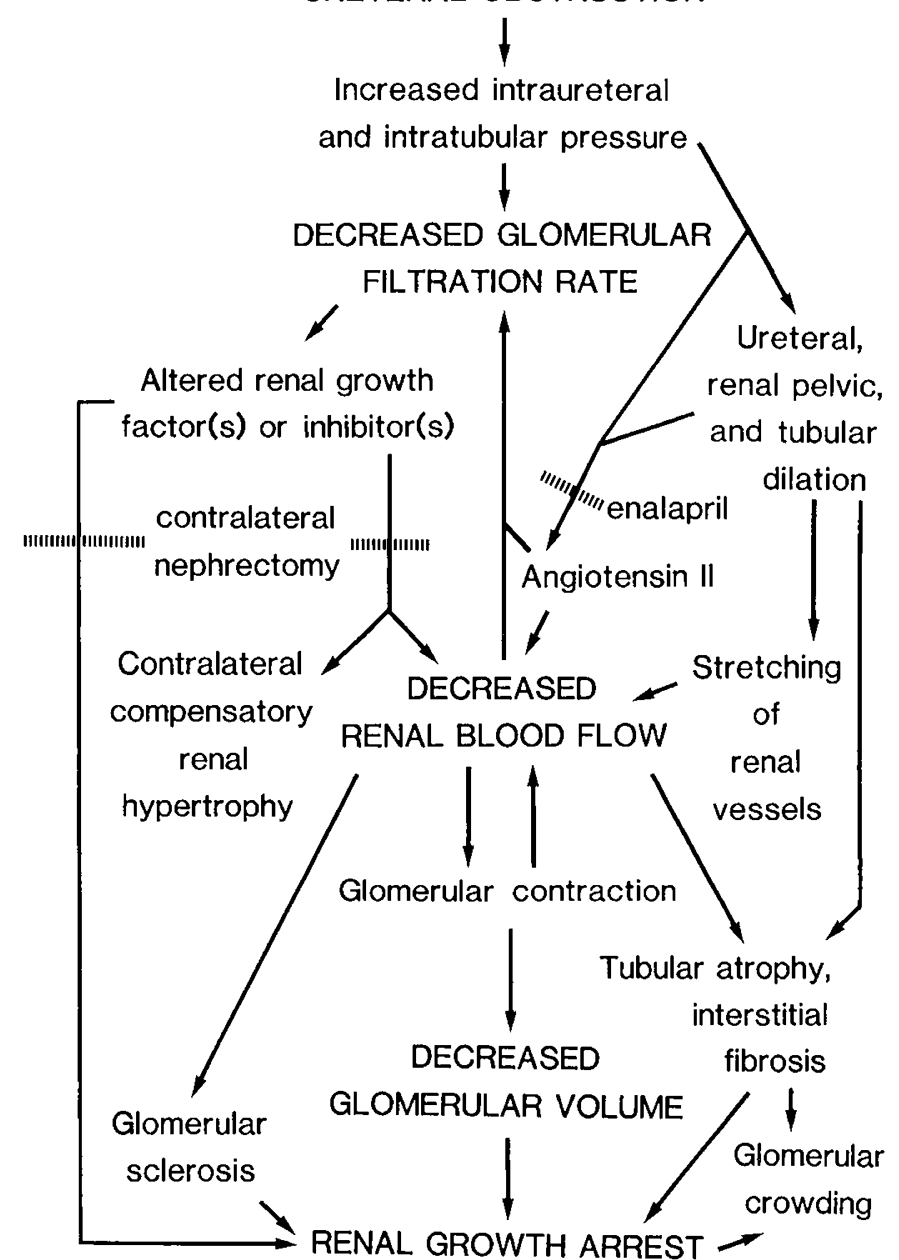

Fig. 4. Proposed pathogenetic development of renal injury. Morphologic findings are related to previously reported physiologic studies. Hatched bars indicate inhibition of effect.

chronic nephron obstruction is mediated at least in part by angiotensin II (22), a finding which is supported by the effects of enalapril in the 3-wk-old guinea pig with CPUO described herein. Although angiotensin converting enzyme inhibition resulted in a partial restoration of RBF in the obstructed kidney, tubular dilatation persists, with development of changes unaffected by enalapril (tubular atrophy and interstitial fibrosis). This suggests that additional factors become important in mediating progressive ischemic injury once CPUO is prolonged beyond $3 \mathrm{wk}$. It is unlikely that stretching and compression of renal vessels by pelvic dilatation (particularly peritubular capillaries and vasa rectae) play a central role in nonangiotensin-mediated ischemia (23).

The pathogenesis of glomerular sclerosis developing after $8 \mathrm{wk}$ CPUO is not certain, but may involve progressive ischemic injury as suggested by microangiographic studies (23). Similar lesions have been described in patients with reflux nephropathy (24). Since the sclerotic glomeruli were small and were not present in the hypertrophied contralateral kidney (or the single kidneys of uninephrectomized control guinea pigs), it is unlikely that injury resulted from hyperfiltration (25). Although administration of enalapril resulted in slight glomerular sclerosis in left (obstructed) kidneys of 3-wk-old animals (30B versus 30BE), there was no glomerular sclerosis in the right kidneys of these groups. Furthermore, there was no effect of enalapril on glomerular sclerosis in either kidney of 3-wk-old sham animals or 8-wk-old animals subjected to CPUO. In addition, there was no effect of enalapril on other histological parameters measured. Therefore, while the slight (but significant) glomerular sclerosis observed in left kidneys of group $30 \mathrm{BE}$ may be related to selectively increased RBF in this group, greater glomerular sclerosis and greater severity of histologic changes in group $80 \mathrm{~B}$ cannot be ascribed to either converting enzyme inhibition or increased RBF.

Based on the present study and our previous physiologic observations in this model, we propose the pathogenetic sequence shown in Figure 4. Ureteral constriction results in elevated intraureteral pressure $(3,4)$ which caused dilatation of the ureter and tubules. RBF is reduced, due in part to action of angiotensin II, and may be increased by enalapril administration during the first $3 \mathrm{wk}$ (4). In addition, stretching and compression of renal vessels by pelvic dilation contributes to reduction in RBF, particularly of the postglomerular circulation (23). Reduced effective filtration pressure due to elevated intratubular pressure, increased angiotensin effect, and reduced renal plasma flow contribute to decreased glomerular filtration rate (2-4). This decrease in excretory function results in altered synthesis or release of renal growth factors or inhibitors causing further reduction in RBF and growth arrest of the obstructed kidney and increased perfusion and compensatory growth of the contralateral kidney. By shifting the excretory burden to the obstructed kidney, contralateral nephrectomy alters the effect of altered renotropic factors, and RBF is maintained. If the opposite kidney is intact, reduced RBF of the obstructed kidney results in ischemic contraction and eventual reduction in glomerular volume and sclerosis, which contribute to renal growth arrest. Decreased renal perfusion and increased intratubular pressure also eventually result in tubular atrophy and interstitial fibrosis which cause glomerular crowding in the obstructed kidney. Prevention or reversal of this proposed sequence should therefore be attempted early in the development of CPUO. Since obstructive nephropathy generally develops in fetal life, at which time the maturing kidney is even more susceptible to damage (26), improved techniques for prenatal intervention will be required to achieve this.

\section{REFERENCES}

1. Reimold EW, Don TD, Worthen HG 1977 Renal failure during the first year of life. Pediatrics 59:987-994

2. Chevalier RL, Kaiser DL 1984 Chronic partial ureteral obstruction in the neonatal guinea pig. I. Influence of uninephrectomy on growth and hemodynamics. Pediatr Res 18:1266-1271

3. Chevalier RL 1984 Chronic partial ureteral obstruction in the neonatal guinea pig. Il. Pressure gradients affecting glomerular filtration rate. Pediatr Res 18:1271-1277

4. Chevalier RL, Peach M 1985 Hemodynamic effects of enalapril on neonatal chronic partial ureteral obstruction. Kidney Int 28:891 -898

5. Wcibel ER 1979 Stereologic Methods, Vol. I. Academic Press, London, pp 4445

6. Chevalier RL 1982 Glomerular number and perfusion during normal and compensatory renal growth in the guinea pig. Pediatr Res 16:436-440

7. Chevalier RL 1983 Hemodynamic adaptation to reduced renal mass in early postnatal development. Pediatr Res 17:620-624

8. Knutson DW, Chieu F, Bennett CM, Glassock RJ 1978 Estimation of relative glomerular capillary surface area in normal and hypertrophic rat kidneys. Kidncy Int 14:437-443

9. John E, Goldsmith DI, Spitzer A 1981 Quantitative changes in the canine glomerular vasculature during development: physiologic implications. Kidney Int 20:223-229

10. Block MA, Wakim KG, Mann FC 1953 ^ppraisal of certain factors influencing compensatory renal hypertrophy. Am J Physiol 172:60-66

11. Preuss HG, Goldin H 1979 A renotropic system in rats. J Clin Invest 57:94101

12. Hayslett JP 1979 Functional adaptation to reduction in renal mass. Physiol Rev 59:137-164

13. Hinman F 1923 Renal counterbalance: an experimental and clinical study with reference to the significance of disuse atrophy. J Urol 9:289-314

14. Chevalier RL 1982 Functional adaptation to reduced renal mass in early development. Am J Physiol 242:F190-F196

15. Hornych H, Beaufils M, Richet G 1972 The effect of exogenous angiotensin on superficial and deep glomeruli in the rat kidney. Kidney Int 2:336-343

16. Weinberger HD, Martin BA, Gattone II VH, Evan AP, Connors BA, Luft FC, Willis LR 1986 The effect of angiotensin II on glomerular function and morphology in the rat. J Submicrose Cytol 18:29-34

17. Dicker SE, Shirley DG 1972 Compensatory hypertrophy of the contralateral kidney after unilateral ureteral ligation. J Physiol 220:199-210 
18. Paulson DF, Fralcy EE 1973 Compensatory renal growth after unilateral ureteral obstruction. Kidney Int 4:22-27

19. Taki M, Goldsmith DI, Spitzer A 1983 Impact of age on effects of ureteral obstruction on renal function. Kidney Int 24:602-609

20. Hayslett JP, Kashgarian M, Epstein FH 1968 Functional correlates of compensatory renal hypertrophy. J Clin Invest 47:774-782

21. Arnold DD 1964 The effect of opposite nephrectomy upon developing experimental open hydronephrosis in the rat. Br J Urol 36:175-183.

22. Carmines PK, Tanner GA 1983 Angiotensin in the hemodynamic response to chronic nephron obstruction. Am J Physiol 245:F75-F82
23. Rao NR, Heptinstall RH 1983 Experimental hydronephrosis: a microangiographic study. Invest Urol 6:183-204

24. Torres VE, Velosa JA, Holley KE, Kelalis PP, Stickler GB, Kurtz SB 1980 The progression of vesicoureteral reflux nephropathy. Ann Intern Med 92:776784

25. Rennke HG 1986 Structural alterations associated with glomerular hyperfiltration. In: Mitch WE, Brenner BM, Stein JH (eds) The Progressive Nature of Renal Disease. Churchill Livingstone, New York, pp 111-131

26. Beck AD 1971 The effect of intra-uterine urinary obstruction upon the development of the fetal kidney. J Urol 106:784-789 